Arq. Bras. Med. Vet. Zootec., v.67, n.2, p.564-572, 2015

\title{
Efeito da adição de teores crescentes de ureia na cana-de-açúcar em dietas de vacas em lactação sobre a produção e composição do leite e viabilidade econômica
}

\author{
[The effect of increasing urea in sugarcane diet of lactating cows on milk production and \\ composition and its economic viability] \\ R.C. Souza ${ }^{1}$, R.B. Reis ${ }^{2}$, F.C.F. Lopez ${ }^{3}$, M.H.F. Mourthe ${ }^{2}$, A.M.Q. Lana ${ }^{2}$, \\ F.A. Barbosa ${ }^{2}$, B.M. Sousa ${ }^{4}$ \\ ${ }^{1}$ Pontifícia Universidade Católica de Minas Gerais - PUC Minas - Betim, MG \\ ${ }^{2}$ Escola de Veterinária - Universidade Federal de Minas Gerais - UFMG - Belo Horizonte, MG \\ ${ }^{3}$ Embrapa Gado de Leite - Juiz de Fora, MG \\ ${ }^{4}$ Faculdade de Estudos Administrativos de Minas Gerais - FEAD-MG - Belo Horizonte, MG
}

\begin{abstract}
RESUMO
Avaliou-se o efeito da adição de teores crescentes de ureia $(0,0 ; 0,5$ e 1,0\%) na matéria natural da canade-açúcar sobre a produção e composição do leite, eficiência alimentar e viabilidade econômica. Foram utilizadas 18 vacas em lactação, com produção média inicial de $21,3 \pm 0,8 \mathrm{~kg} /$ dia de leite e com $83 \pm 7$ dias em lactação, distribuídas em delineamento ensaio de reversão do tipo switch-back, 3x3. As dietas experimentais foram constituídas de cana-de-açúcar como volumoso único e concentrado, na relação de 50:50 (base MS). Não houve efeito da suplementação dos diferentes teores de ureia sobre a produção e composição do leite. Contudo, a eficiência alimentar (produção de leite/consumo de matéria seca) foi melhor nas dietas em que se utilizou ureia, sendo 1,$14 ; 1,17$ e 1,17 , respectivamente, para as dietas com 0,$0 ; 0,5$ e $1,0 \%$ de ureia $(\mathrm{P}<0,05)$. Considerando-se apenas o custo alimentar, todas as dietas apresentaram saldo positivo, sendo que a dieta com $1,0 \%$ de ureia apresentou o melhor saldo.
\end{abstract}

Palavras-chave: bovino, componentes do leite, custo

\begin{abstract}
We studied the effect of increasing 0.0, 0.5 and 1.0\% urea in natural sugar cane on cow milk production and composition, food productivity and economic viability. Eighteen lactating cows were studied, they had avarage milk production of $21.3 \pm 0.8 \mathrm{~kg} /$ day and were $83 \pm 7$ days in lactation in a switch-back, $3 \times 3$ design. The experimental diets consisted of a unique concentrated sugar cane portion with the 50:50 relation (MS base). The results showed no effect of different urea concentrations on the milk production or composition. However, food productivity (milk production/dry matter consumption) was 1.14; 1.17, and 1.17 respectively on urea diets of $0.0 ; 0.5$ and $1.0 \%(P<0.05)$. Considering only the alimentary cost, all diets had a positive balance, and the $1.0 \%$ urea concentration was the best.
\end{abstract}

Keywords: cattle, milk componentes, cost

\section{INTRODUÇÃO}

A maioria dos sistemas de produção de leite no Brasil possui como principal fonte de volumoso o pasto, que se caracteriza por apresentar elevada produção de massa de forragem durante a estação chuvosa do ano. No entanto, na estação fria e seca, a produção de matéria seca dessas forrageiras diminui drasticamente, fazendo-se necessária suplementação volumosa. Com esse objetivo, a cana-de-açúcar ocupa lugar de destaque, devido ao fato de sua maior disponibilidade de MS e açúcares conincidir com a escassez de produção de forragem das outras gramíneas tropicais.

Recebido em 1 de julho de 2014 
No entanto, para potencializar a utilização da cana-de-açúcar como alimento volumoso, faz-se necessário corrigir adequadamente suas principais limitações nutricionais, e, dentre elas, destaca-se seu baixo teor de proteína bruta. Com esse intuito, a suplementação com ureia, uma fonte de nitrogênio não proteico, em dietas à base de cana de açúcar, tem sido pesquisada no Brasil desde a década de 60. Assim, a partir do trabalho de Castro (1967) e, posteriormente, dos de Moreira (1983), Vilela et al. (1985) e de Moreira e Mello (1986), foi consolidada a clássica recomendação de se adicionar $1,0 \%$ de ureia na matéria natural da cana-de-açúcar. Todavia, tal recomendação foi feita para níveis de produção animal aquém dos observados nos atuais rebanhos leiteiros. Além disso, esses autores utilizaram bovinos em crescimento, e não vacas em lactação. Dessa forma, o teor máximo de suplementação com nitrogênio não proteico para vacas de nível de produção mais elevado em dietas à base de cana-de-açúcar é questionável, já que estudos mais recentes (Aquino et al., 2008; Aguiar et al., 2013) mostraram resultados divergentes quanto à quantidade adequada de ureia a ser suplementada na cana-de-açúcar.

$\mathrm{O}$ excesso de ureia adicionado em dietas à base de cana-de-açúcar pode ocasionar ineficiência alimentar em função do gasto adicional de energia pelo animal, decorrente da necessidade de conversão em ureia, no fígado, da amônia circulante no sangue absorvida do rúmen. Além disso, representa potencial de contaminação ambiental, já que parte da ureia proveniente do fígado é excretada via urina. Ressalte-se ainda que efeitos negativos sobre a eficiência reprodutiva das vacas têm sido relacionados ao excesso de amônia no sangue (Butler, 1998).

Foi objetivo deste estudo avaliar a produção e composição do leite e a viabilidade econômica da inclusão de teores crescentes $(0,0,5$ e $1,0 \%)$ de ureia na matéria natural da cana-de-açúcar in natura na dieta de vacas Holandês x Gir com produção acima de $20 \mathrm{~kg} /$ dia de leite.

\section{MATERIAL E MÉTODOS}

O experimento foi realizado no Campo Experimental José Henrique Bruschi, de propriedade da Embrapa Gado de Leite, localizado em Coronel Pacheco (MG). Foram utilizadas 18 vacas Holandês x Gir, sendo 12 multíparas e seis primíparas, com produção média inicial de $21,3 \pm 0,8 \mathrm{~kg} / \mathrm{dia}$ de leite e com $83 \pm 7$ dias em lactação.

As vacas foram alojadas em curral do tipo free stall, com água e mistura mineral ad libitum, e equipado com cochos dotados de portões eletrônicos do tipo calan-gate (American Calan Inc., Northewood, EUA). As dietas experimentais basearam-se na utilização de canade-açúcar (cultivar RB 73-9735) in natura picada, como volumoso único, e enriquecida com misturas de $0 ; 0,5$ ou 1,0\% de ureia:sulfato de amônio (9:1) em relação à matéria natural, sendo formuladas com farelo de soja, fubá de milho, caroço de algodão, suplemento mineralvitamínico, calcário e tamponante (Tab. 1).

O delineamento experimental utilizado foi ensaio de reversão do tipo switch-back, $3 \times 3$, com seis vacas aleatoriamente distribuídas em cada um dos tratamentos experimentais. Dois grupos foram constituídos de vacas multíparas e um grupo, de primíparas. A duração dos períodos experimentais foi de 21 dias, sendo 14 dias de adaptação às dietas e sete de coleta de dados/amostras. As vacas foram pesadas no primeiro dia de cada período experimental, sempre após a ordenha da manhã e antes do fornecimento do trato diário.

As dietas foram formuladas para serem isoproteicas $(15,4 \%$ de $\mathrm{PB})$ e isoenergéticas $(68,9 \%$ de nutrientes digestíveis totais - NDT), segundo o NRC (Nutrient..., 2001), e com concentrações de fibra em detergente neutro (FDN) e ácido (FDA) o mais uniforme possíveis, além de igual relação volumoso:concentrado de 50:50\% (base MS), conforme apresentado nas Tabelas 1 e 2.

As dietas foram fornecidas na forma de mistura completa (TMR - total mixed ration), uma vez ao dia, às 7 horas da manhã, sendo preparadas em vagão misturador semiautomatizado e computadorizado (DATARANGER ${ }^{\circledR}$, American Calan Inc., Northewood, NH, EUA), de modo a permitir em torno de $10 \%$ de sobras. 
Tabela 1. Composição de ingredientes das dietas experimentais, baseadas em cana-de-açúcar in natura como volumoso único e enriquecidas com ureia

\begin{tabular}{lccc} 
& \multicolumn{3}{c}{ Teores de ureia (\% da matéria natural da cana- } \\
Item & 0,0 & 0,5 & 1,0 \\
\cline { 2 - 3 } & Ingredientes $(\%$ da & matéria seca) \\
Cana-de-açúcar & 50,00 & 50,00 & 50,00 \\
Caroço de algodão & 6,90 & 6,90 & 6,90 \\
Fubá de milho & 10,40 & 15,3 & 20,35 \\
Farelo de soja & 30,25 & 24,52 & 18,89 \\
Ureia pecuária & 0,00 & 0,84 & 1,56 \\
Bicarbonato de sódio & 0,75 & 0,75 & 0,75 \\
Calcário calcítico & 1,00 & 1,00 & 0,90 \\
Suplemento mineral-vitamínico ${ }^{1}$ & 0,40 & 0,40 & 0,40 \\
Cloreto de sódio & 0,30 & 0,30 & 0,30 \\
\hline
\end{tabular}

${ }^{1}$ Suplemento mineral-vitamínico (Composição por kg): Co 0,200 ppm; Cu 10,000 ppm; Fe 0,105 ppm; I 0,500 ppm; Mn 14,000 ppm; Se 0,290 ppm; Zn 43,000 ppm; vit. A 12.000.000 UI; vit. D 3.100.000 UI; vit. E 75.000 UI.

Do $15^{\circ}$ ao $21^{\circ}$, foram feitas amostragens diárias individualizadas das dietas oferecidas, das sobras, bem como da cana-de-açúcar e ingredientes dos suplementos concentrados. Essas amostras foram armazenadas em congelador $\left(-20^{\circ} \mathrm{C}\right) \quad$ e, posteriormente, descongeladas, pré-secadas em estufa de ventilação forçada de $\operatorname{ar}\left(55^{\circ} \mathrm{C}, 72 \mathrm{~h}\right)$, moídas em moinho de facas tipo Willey (peneira com perfurações de $1 \mathrm{~mm}$ ), compostas por tratamento ou por animal $\mathrm{x}$ fase (conforme o tipo de amostra) e analisadas quanto aos teores de matéria seca total, matéria orgânica (MO), proteína bruta, hemicelulose, celulose, lignina, cinzas, extrato etéreo (EE), fibra em detergente neutro (FDN) e ácido (FDA), conforme Detmann et al. (2012). As análises químicas dos alimentos foram realizadas no Laboratório de Análise de Alimentos da Embrapa Gado de Leite (Juiz de Fora, MG).

Do $19^{\circ}$ ao $20^{\circ}$ dia de cada período de coleta, foi realizado o registro das produções individuais de leite de quatro ordenhas consecutivas e, após a homogeneização do leite ordenhado de cada vaca, foram coletadas, em frascos contendo bronopol como conservante, amostras representativas das produções individuais diárias, visando a análises dos componentes do leite, que foram realizadas no Laboratório de Qualidade do Leite da Embrapa Gado de Leite (Juiz de Fora, MG), pelo método de raios infravermelhos proximais, utilizando-se o aparelho Bentley 2000 (Bentley Instruments, Chaska, EUA). As concentrações de nitrogênio ureico no leite (NUL) foram analisadas na Clínica do Leite (Piracicaba, SP), pelo método colorimétricoenzimático, utilizando-se o aparelho Chemspec 150 (Bentley Instruments, Chaska, EUA).

As produções de leite corrigidas para $4 \%$ de gordura (LCG) e para sólidos totais (LCST) foram calculadas segundo Tyrrell e Reid (1965): LCG $=($ Produção de leite $\times 0,4) \times$ (Produção de Gordura x 15) e LCST $=[(12,3 \times$ produção de gordura $)+(6,56$ x extrato seco desengordurado $)$ - $(0,0752 \times$ produção de leite $)]$.

A eficiência alimentar (EFA) para produção de leite foi calculada pela fórmula: EFA para produção de leite $=\mathrm{kg}$ de leite produzido por dia/g de MS consumida por dia. A eficiência de utilização do nitrogênio da dieta em proteína do leite foi obtida pela equação: nitrogênio no leite (proteína do leite/6,38), kg/nitrogênio consumido, $\mathrm{kg}$. 
Efeito da adição de teores...

Tabela 2. Composição bromatólogica das dietas experimentais baseadas em cana-de-açúcar in natura como volumoso único e enriquecidas com ureia

\begin{tabular}{lccc}
\hline \multirow{2}{*}{ Item } & \multicolumn{2}{c}{ Teores de ureia (\% da matéria natural da cana-de-açúcar) } \\
\cline { 2 - 3 } & 0,0 & 0,5 & 1,0 \\
\hline \multirow{2}{*}{ Matéria seca (\%) } & 44,9 & 44,9 & 44,9 \\
Matéria orgânica & 87,59 & 87,96 & 86,33 \\
Proteína bruta & 16,23 & 16,89 & 16,62 \\
Fibra em detergentélogica $(\%$ da matéria seca) & 36,39 \\
Fibra em detergente ácido & 33,46 & 34,75 & 25,27 \\
Hemicelulose & 23,23 & 22,94 & 10,81 \\
Celulose & 10,23 & 11,81 & 18,55 \\
Lignina & 17,13 & 16,86 & 5,26 \\
Carboidratos não-fibrosos ${ }^{1}$ & 4,63 & 4,51 & 38,43 \\
Extrato etéreo & 41,43 & 39,80 & 2,23 \\
Cinzas & 2,35 & 1,99 & 6,33 \\
\hline
\end{tabular}

${ }^{\mathrm{T}} \mathrm{CNF}=100-(\% \mathrm{~PB}+\% \mathrm{FDNcorrigido}+\% \mathrm{EE}+\%$ Cinzas $)$, conforme descrito em Sniffen et al. (1992).

Para análise da economicidade das dietas, foi utilizado o preço médio do leite recebido (R\$ 0,54) na folha de receita da Embrapa Gado de Leite (Juiz de Fora, MG), durante os meses de realização do experimento, de julho a setembro de 2007. O preço dos concentrados foi calculado em função dos preços dos ingredientes comprados em junho de 2007 (Tab. 3).

Foi usado o termo "Saldo" em substituição da margem bruta para expressar os resultados, uma vez que estão sendo avaliados somente os gastos com alimentação.

Tabela 3. Preços dos insumos utilizados na composição do custo das dietas experimentais

\begin{tabular}{lc} 
Alimentos & $\mathrm{R} \$ / \mathrm{kg}$ de matéria seca \\
\hline Cana-de-açúcar & \\
Caroço de algodão & 0,0350 \\
Fubá de milho & 0,5000 \\
Farelo de soja & 0,4500 \\
Ureia pecuária & 0,6600 \\
Bicarbonato de sódio & 1,4000 \\
Calcário calcítico & 1,3000 \\
Premix mineral-vitamínico & 0,1400 \\
Cloreto de sódio & 1,2260 \\
\hline
\end{tabular}

${ }^{1}$ Fonte: Fernandes et al. (2007).

Os resultados foram analisados utilizando-se o procedimento GLM do software estatístico SAS versão 9.0, sendo a comparação das médias realizada por meio do LSMEANS $(\mathrm{P}<0,05)$. Foi utilizado o comando ESTIMATE do SAS para avaliação do efeito linear dos tratamentos.
Este estudo foi realizado de acordo com os Princípios Éticos da Experimentação Animal, adotados pelo Comitê de Ética em Experimentação Animal (CETEA/UFMG), tendo sido aprovado na reunião de 08/10/2008. 


\section{RESULTADOS E DISCUSSÃO}

Os consumos de MS foram de 19,64; 19,66 e $18,33 \mathrm{~kg} /$ dia para as dietas com 0,$0 ; 0,5$ e $1,0 \%$ de ureia, respectivamente, na matéria natural da cana-de-açúcar. As vacas que receberam dieta com $1,0 \%$ de ureia apresentaram menor $(\mathrm{P}<0,05)$ consumo de MS em comparação ao das outras duas dietas, que foram semelhantes entre si $(\mathrm{P}>0,05)$.

As produções diárias de leite, a de leite corrigida para $4 \%$ de gordura, leite corrigida para teor de sólidos totais e componentes do leite, não foram afetadas pelo diferentes teores de ureia na matéria natural da cana-de-açúcar $(\mathrm{P}>0,05)$ (Tab. 4).
Trabalhando com dietas compostas por $40 \%$ de cana-de-açúcar suplementadas com $60 \%$ de concentrados (base MS), contendo 0; 0,75 e $1,5 \%$ de ureia na MS total da dieta, Aquino et al. (2007) não relataram diferença $(\mathrm{P}>0,05)$ na produção e composição do leite, sendo os valores observados por esses autores próximos aos encontrados no presente estudo. Os valores de produção de leite observados também foram próximos àqueles relatados por Mendonça et al. (2004), que compararam dietas à base de canade-açúcar com relação V:C de 60:40 com 0,35 ou $1 \%$ de ureia e relação $\mathrm{V}: \mathrm{C}$ de $50: 50$ com $1 \%$ de ureia.

Tabela 4. Produções de leite, de gordura e de proteína, e eficiência alimentar de vacas recebendo dietas à base de cana-de-açúcar in natura como volumoso único e enriquecidas com ureia

\begin{tabular}{|c|c|c|c|c|c|}
\hline \multirow[b]{2}{*}{ Variável } & \multicolumn{3}{|c|}{$\begin{array}{c}\text { Teores de ureia } \\
(\% \text { na MN da cana-de-açúcar })^{1}\end{array}$} & \multirow{2}{*}{$\mathrm{EPM}^{2}$} & \multirow{2}{*}{$\begin{array}{c}\text { Efeito } \\
\text { Linear }^{3}\end{array}$} \\
\hline & 0,0 & 0,5 & 1,0 & & \\
\hline \multicolumn{6}{|c|}{ Produção (kg/vaca/dia) } \\
\hline Leite & 21,8 & 21,8 & 22,1 & 0,1109 & 0,5050 \\
\hline Leite corrigida para $4 \%$ de gordura & 21,0 & 21,1 & 21,4 & 0,1722 & 0,4276 \\
\hline Leite corrigida para teor de sólidos & 20,2 & 20,1 & 20,5 & 0,2091 & 0,3318 \\
\hline Gordura & 0,86 & 0,86 & 0,87 & 0,0097 & 0,2167 \\
\hline Proteína & 0,74 & 0,74 & 0,76 & 0,0095 & 0,2033 \\
\hline \multicolumn{6}{|c|}{ Eficiência alimentar } \\
\hline $\mathrm{EPL}^{4}$ & $1,15 b$ & $1,17 \mathrm{a}$ & $1,17 \mathrm{a}$ & 0,0600 & 0,2509 \\
\hline Leite corrigida para $4 \%$ de gordura ${ }^{5}$ & 1,12 & 1,10 & 1,11 & 0,0363 & 0,3148 \\
\hline $\mathrm{N}$ leite/ $\mathrm{N}$ consumido ${ }^{6}$ & 0,2358 & 0,2359 & 0,2388 & 0,0054 & 0,4835 \\
\hline
\end{tabular}

${ }^{\mathrm{T}}$ Médias seguidas de letras distintas nas linhas são diferentes $(\mathrm{P}<0,05) ;{ }^{2} \mathrm{EPM}=$ erro padrão da média; ${ }^{3}$ Valor do $\mathrm{P}$; ${ }^{4} \mathrm{EPL}=$ eficiência alimentar para produção de leite $\left(\mathrm{kg}\right.$ de leite/kg de MS); ${ }^{5} \mathrm{PLG}=$ eficiência alimentar para produção de leite corrigida $4 \%$ de gordura ( $\mathrm{kg}$ de LCG4\% $/ \mathrm{kg}$ de MS); ${ }^{6} \mathrm{~N}=$ nitrogênio.

Em contrapartida, Oliveira et al. (2001), Silva et al. (2001) e Oliveira et al. (2004), avaliando dietas com silagem de milho como fonte de volumoso, com inclusão de 0,$0 ; 0,7 ; 1,4 \%$ e $2,1 \%$ de ureia na dieta total de vacas em lactação, observaram efeito linear negativo do nível de inclusão de ureia sobre a produção de leite, explicado pelo menor consumo de MS.

A eficiência alimentar para produção de leite foi semelhante $(\mathrm{P}>0,05)$ nas dietas com 0,5 e $1,0 \%$, sendo maiores $(\mathrm{P}<0,05)$ em relação à dieta com $0 \%$ de ureia. Entretanto, não houve diferença na eficiência para produção de leite corrigida para
4,0\% de gordura e utilização do nitrogênio $(\mathrm{P}>0,05)$ (Tab. 4). Apesar de melhor eficiência alimentar nas dietas com 0,5 e $1,0 \%$, os valores foram baixos quando comparados aos de dietas com silagem de milho como volumoso, o que reforça a necessidade de melhorar a eficiência alimentar em dietas com cana-de-açúcar e ureia, com a utilização de cultivares de cana-de-açúcar de melhor qualidade, manejo ao corte para melhorar a digestibilidade da fibra, e outras fontes de energia, com o intuito de sincronizar com a produção de amônia ruminal. 
Um dos possíveis fatores que podem explicar a maior eficiência alimentar para a produção de leite nas dietas com 0,5 e 1,0\% de ureia refere-se à maior disponibilidade de amido nestas, que pode ter favorecido melhor utilização de amônia e, possivelmente, maior síntese de proteína microbiana (Van Soest, 1994).

Não foi observado efeito linear $(\mathrm{P}>0,05)$ da concentração dietética de ureia sobre as variáveis de composição do leite (Tab. 5). No entanto, os teores de proteína e gordura foram elevados quando comparados aos relatados nos estudos de Aquino et al. (2007) e Jesus et al. (2011), que utilizaram como fonte de volumoso cana-deaçúcar com inclusão de 0,$0 ; 0,75$ e 1,5\% de ureia na MS total, e de Carmo et al. (2005), que utilizou silagem de capim como fonte de volumoso com inclusão de $2,0 \%$ de ureia na MS total. Isso pode indicar eficiência na fermentação e síntese de proteína microbiana ruminal, como também menor efeito diluidor em função da produção dos animais.

Tabela 5. Composição do leite de vacas recebendo dietas à base de cana-de-açúcar in natura como volumoso único e enriquecidas com ureia

\begin{tabular}{|c|c|c|c|c|c|}
\hline \multirow[b]{2}{*}{ Variável } & \multicolumn{3}{|c|}{$\begin{array}{l}\text { Teores de ureia (\% na matéria natural da } \\
\text { cana-de-açúcar) }{ }^{1}\end{array}$} & \multirow{2}{*}{$\mathrm{EPM}^{2}$} & \multirow{2}{*}{$\begin{array}{l}\text { Efeito } \\
\text { Linear }^{3}\end{array}$} \\
\hline & 0,0 & 0,5 & 1,0 & & \\
\hline \multicolumn{6}{|c|}{ Composição (\%) } \\
\hline Gordura & 4,06 & 4,09 & 4,03 & 0,0351 & 0,8007 \\
\hline Proteína & 3,46 & 3,42 & 3,43 & 0,0124 & 0,9108 \\
\hline Lactose & 4,62 & 4,63 & 4,62 & 0,0066 & 0,4187 \\
\hline Extrato seco total & 13,17 & 13,16 & 13,10 & 0,0377 & 0,8633 \\
\hline Extrato seco desengordurado & 9,10 & 9,07 & 9,08 & 0,0100 & 0,8812 \\
\hline Nitrogênio ureico (mg/dL) & 18,99 & 19,90 & 19,74 & 0,4173 & 0,1620 \\
\hline
\end{tabular}

${ }^{1}$ Não houve diferença entre tratamentos $(\mathrm{P}>0,05) ;{ }^{2} \mathrm{EPM}=$ erro padrão da média; ${ }^{3}$ Valor do $\mathrm{P}$.

A concentração de nitrogênio ureico do leite (NUL) variou de 18,99 a $19,90 \mathrm{mg} / \mathrm{dL}$, sendo semelhante entre as dietas $(\mathrm{P}>0,05)$ (Tab. 5), valores estes considerados altos quando comparados ao recomendado por Linn e Olson (1995), que consideraram como normal teor de até $18 \mathrm{mg} / \mathrm{dL}$. Diversos fatores podem alterar a concentração de NUL, dentre eles, o teor de proteína degradável no rúmen (PDR) e proteína não degradável no rúmen da dieta (PNDR). Segundo Linn e Olson (1995), concentrações de NUL superiores a $18 \mathrm{mg} / \mathrm{dL}$ e teor de proteína do leite acima de 3,2\% representariam excesso de proteína PDR/PNDR em relação ao consumo de carboidratos fermentáveis e energia líquida. Todavia, apesar de o tratamento com $1 \%$ de ureia apresentar maior teor de PDR, nenhum efeito $(\mathrm{P}>0,05)$ foi observado sobre o NUL quando comparado com o das dietas com 0,0 e $0,5 \%$.

Apesar de não ter sido objetivo específico do presente estudo, há sempre que se preocupar com o efeito do NUL sobre a eficiência reprodutiva das vacas. Nesse sentido, Butler (1998) verificou que teor de NUL acima de $19 \mathrm{mg} / \mathrm{dL}$ ocasionou redução da concentração plasmática de progesterona e alteração do $\mathrm{pH}$ do ambiente uterino, relacionando alteração destes parâmetros como principais causas de redução da fertilidade em vacas no início da lactação. Contudo, em estudo mais recente, Bezerra et al. (2009) observaram que teor de NUL de até $26 \mathrm{mg} / \mathrm{dL}$ não afetou a eficiência reprodutiva de vacas Girolandas.

Oliveira et al. (2004) observaram que não houve efeito (P>0,05) sobre o NUL $(19,17$ a $20,48 \mathrm{mg} / \mathrm{dL})$ em função do nível de inclusão de ureia $(0,0 ; 0,7 ; 1,4$ e $2,1 \%$ na MS total) em dietas à base de silagem de milho fornecidas para vacas mestiças. Já Aquino et al. (2008) observaram valores mais baixos $(17,28$ a $17,97 \mathrm{mg} / \mathrm{dL})$ ao avaliarem dietas compostas de farelo de soja como principal fonte proteica e cana-de-açúcar como volumoso, com $0 ; 0,75$ ou $1,5 \%$ de ureia em substituição ao farelo de soja. 
Segundo Broderick e Clayton (1997), um dos principais fatores que afetam o teor de NUL é a concentração de PB da dieta $\left(r^{2}=0,839\right)$. Sendo assim, considerando-se a produção de leite e o estádio de lactação em que as vacas se encontravam (DEL \pm 83 ), os teores de PB das dietas $(16,23 ; 16,89$ e $16,62 \%$ PB na MS) estavam acima do recomendado pelo NRC (Nutrient..., 2001), que é de $15,43 \%$ PB na MS da dieta. Tal fato pode ter contribuído para o aumento dos teores de NUL do leite observados no presente estudo.
Na Tabela 6, são apresentados os valores da produção, os preços dos concentrados e dos volumosos das dietas experimentais. A variação do peso vivo não foi considerada porque não houve diferença $(\mathrm{P}>0,05)$ entre as dietas. A dieta com $1,0 \%$ de ureia apresentou maior saldo ( $\mathrm{R} \$$ $6,36)$ por animal em relação às que utilizaram 0,0 e $0,5 \%$ em sua formulação ( $R$ \$ 5,67 e $R$ \$ 5,63, respectivamente). Os saldos por vaca na dieta com $1,0 \%$ de ureia foram $11,47 \%$ e $10,85 \%$ maiores do que nas dietas com $0,0 \%$ e $0,5 \%$ de ureia, respectivamente.

Tabela 6. Gastos com alimentação e saldo por vaca em dietas à base de cana-de-açúcar in natura como volumoso único e enriquecidas com ureia

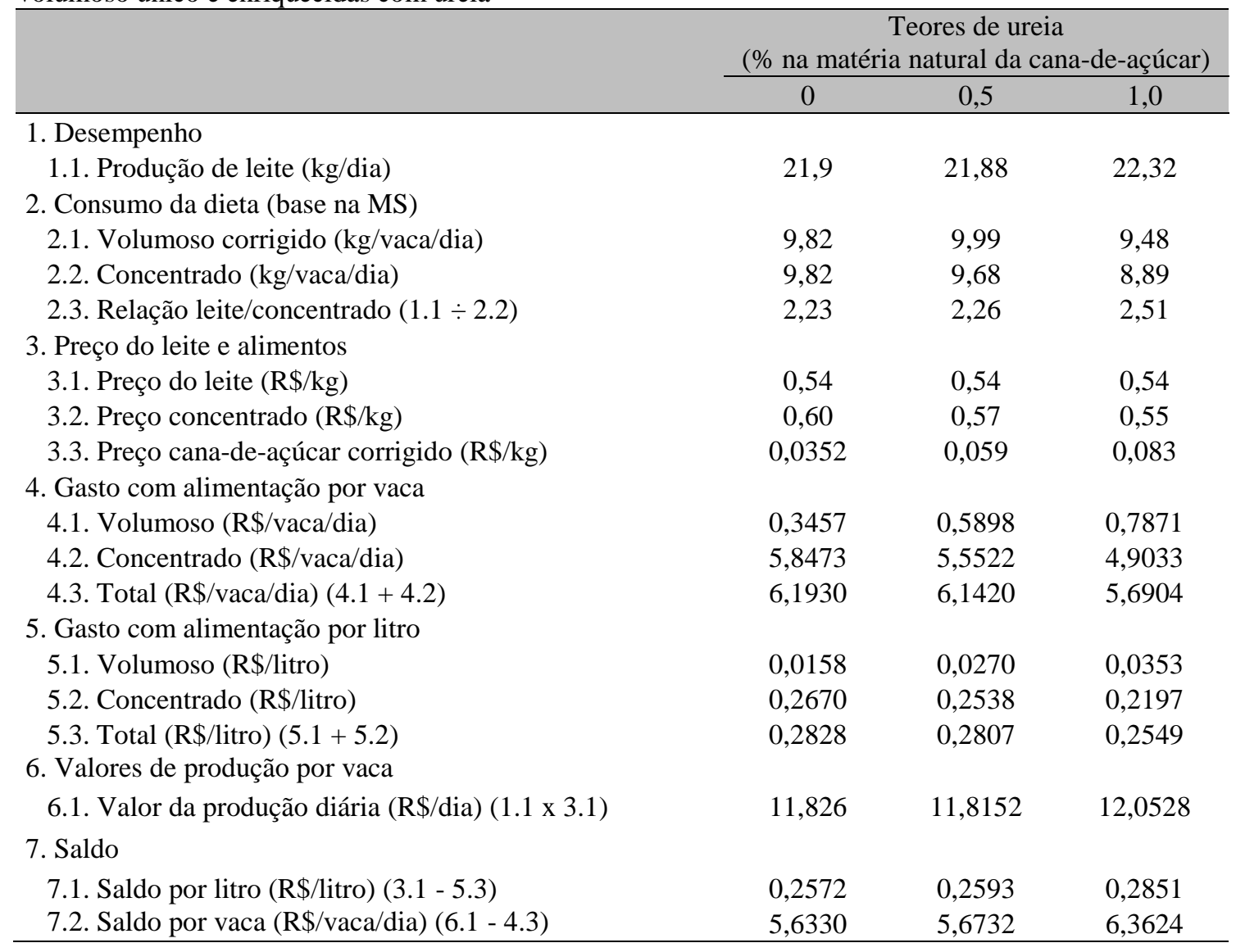

O maior saldo alimentar por vaca na dieta com $1 \%$ de ureia em relação às demais pode estar relacionado com a maior eficiência alimentar nesse tratamento (Tab. 4) e com o menor gasto com concentrado em função da inclusão da ureia em substituição ao farelo de soja. O quilograma de PB proveniente da ureia ( $\mathrm{R} \$ 0,49)$ foi $65,97 \%$ menor do que o do farelo de soja $(\mathrm{R} \$ 1,46)$.
Segundo Reis et al. (2001), considerando os custos totais de um sistema de produção de leite, os gastos com alimentação são os mais elevados, em torno de 45,83\%, necessitando assim de maior eficiência no manejo nutricional. Dessa forma, a cana-de-açúcar com ureia torna-se opção alimentar interessante. Outros trabalhos (Souza, 2003; Magalhães et al., 2004; Mendoça 
et al., 2004) também comprovaram a viabilidade do uso de cana-de-açúcar como volumoso para vacas leiteiras de maior potencial de produção em função dos índices produtivos e econômicos obtidos.

Contudo, apesar de bons resultados na produção de leite, ressalta-se a importância de monitorar o escore da condição corporal dos animais para que a eficiência reprodutiva não seja afetada.

\section{CONCLUSÃO}

A inclusão de 0,0; 0,5 e 1,0\% de ureia na matéria natural da cana-de-açúcar in natura não afetou a produção e a composição do leite. Todas as dietas apresentaram saldo positivo para custo alimentar. A dieta com inclusão de $1 \%$ de ureia na matéria natural da cana-de-açúcar foi a que apresentou melhor saldo por vaca.

\section{AGRADECIMENTOS}

À Fapemig, pelo financiamento do trabalho.

\section{REFERÊNCIAS}

AGUIAR, A.C.R.; OLIVEIRA, C.R.; CALDEIRA, L.A. et al. Consumo, produção e composição do leite e do queijo de vacas alimentadas com níveis crescentes de ureia. Rev. Bras. Cienc. Vet., v.20, p.37-42, 2013.

AQUINO, A.A.; BOTARO, B.C.; IKEDA, F.S. et al. Efeito de níveis crescentes de ureia na dieta de vacas em lactação sobre a produção e a composição físico-química do leite. Rev. Bras. Zootec., v.36, p.881-887, 2007.

AQUINO, A.A.; LIMA, Y.V.R.; BOTARO, B.G. et al. Effects of dietary urea levels on milk protein fractions of Hostein cows. Anim. Feed Sci. Tech., v.140, p.191-198, 2008.

BESERRA, E.E.A.; VIEIRA, R.J.; SOUZA, J.A.T. et al. Efeito do nitrogênio ureico no leite sobre a eficiência reprodutiva de vacas da raça Girolando. Rev. Cient. Prod. Anim., v.11, p.3445, 2009.

BRODERICK, G.A.; CLAYTON, M.K. A statistical evaluation of animal and nutritional factors influencing concentrations of milk urea nitrogen. J. Dairy Sci., v.80, p.2964-2971, 1997.
BUTLER, W.R. Effect of protein nutrition on ovarian and uterine physiology in dairy cattle. $J$. Dairy Sci., v.81, p.2533-2539, 1998.

CARMO, C.A.; SANTOS, F.A.P.; IMAIZUMI, H. et al. Substituição do farelo de soja por ureia ou amireia para vacas em final de lactação. Acta Sci., v.27, p.277-286, 2005.

CASTRO, A.C.G. Cana-de-açúcar "versus" silagem de milho na produção de leite. 1967. 37f. Dissertação (Mestrado em Zootecnia) Universidade Federal de Viçosa, Viçosa, 1967.

DETMANN, E.; SOUZA, M.A.; VALADARES FILHO, S.C. et al. Métodos para Análise de Alimentos - INCT - Ciência Animal. 1.ed. Visconde do Rio Branco: Suprema, 2012. 214p.

FERNANDES, A.R.M.; SAMPAIO, A.A.M.; HENRIQUE, W. et al. Avaliação econômica e desempenho de machos e fêmeas Canchim em confinamento alimentados com dietas à base de silagem de milho e concentrado ou cana-deaçúcar e concentrado contendo grãos de girassol. Rev. Bras. Zootec., v.36, p.855-864, 2007.

JESUS, E.F. Fontes nitrogenadas e teor de proteína bruta em dietas com cana-de-açúcar para vacas lactantes: consumo, digestibilidade, fermentação ruminal, balanço de energia, produção e composição do leite. 2011. 71f. Dissertação (Mestrado em Ciências) - Faculdade de Medicina Veterinária e Zootecnia, Universidade de São Paulo, Pirassununga.

LINN, J.G.; OLSON, J.D. Using milk urea nitrogen to evaluate diets and reproductive performance of dairy cattle. In: STATE APPLIED NUTRICION AND MANAGEMENT, 4., 1995, Wisconsin. Anais...Wisconsin: [s.n.] 1995. p.155-167.

MAGALHÃES, A.L.R.; CAMPOS, J.M.S.; VALADARES FILHO, S.C. et al. Cana-deaçúcar em substituição à silagem de milho em dietas para vacas em lactação: desempenho e viabilidade econômica. Rev. Bras. Zootec., v.33, p.1292-1302, 2004.

MENDONÇA, S.S.; CAMPOS, J.M.S.; VALADARES FILHO, S.C. et al. Consumo, digestibilidade aparente, produção e composição do leite e variáveis ruminais em vacas leiteiras alimentadas com dietas à base de cana-de-açúcar. Rev. Bras. Zootec., v.33, p.481-492, 2004. 
MOREIRA, H.A. Cana-de-açúcar na alimentação de bovinos. Inf. Agropec., v.9, p.1416, 1983.

MOREIRA, H.A.; MELLO, R.P. Cana-deaçúcar e ureia: novas perspectivas para alimentação de bovinos na época da seca. Coronel Pacheco: EMBRAPA-CNPGL, 1986. $18 \mathrm{p}$.

NUTRIENT requeriments of dairy cattle. 7.ed. Washinton: National Research Council, 2001. $381 \mathrm{p}$.

OLIVEIRA, A.S.; VALADARES, R.F.D.; VALADARES FILHO, S.C. et al. Produção de proteína microbiana e estimativas das excreções de derivados de purinas e de ureia em vacas lactantes alimentadas com rações isoproteicas contendo diferentes níveis de compostos nitrogenados não-proteicos. Rev. Bras. Zootec., v.30, p.1621-1629, 2001.

OLIVEIRA, M.M.N.F.; TORRES, C.A.A.; VALADARES FILHO, S.C. et al. Urea for postpartum dairy cows: productive and reproductive performance. R. Bras. Zootec., v.33, p.266-2273, 2004.
REIS, R.P.; MEDEIROS, A.L.; MONTEIRO, L.A. Custo de Produção da Atividade Leiteira na Região Sul de Minas Gerais. Org. Rurais $e$ Agroind., v.3, p.45-54, 2001.

SILVA, R.M.N.; VALADARES， R.F.D.; VALADARES FILHO, S.C. et al. Ureia para vacas em lactação. 1. Consumo, digestibilidade, produção e composição do leite. Rev. Bras. Zootec., v.30, p.1639-1649, 2001.

SNIFFEN, C.J; O'CONNOR, J.D.; VAN SOEST, P.J. et al. A net carbohydrate and protein system for evaluating cattle diets: II. Carbohydrate and protein availability. J. Anim. Sci., v.70, p.3562-3577, 1992.

TYRREL, H.F.; REID, J.T. Prediction of energy value of cows milk. J. Dairy Sci., v.48, p.12151223, 1965.

VAN SOEST, P.J. Nutritional ecology of the ruminant, 2.ed. Ithaca: Cornell University Press, 1994. 476p.

VILELA, H.; SILVESTRE, J.R.A. 1.ed. Ureia: informe técnico. Brasília: EMBRATER, 1985. $57 \mathrm{p}$. 